\title{
Decentrale selectie: mislukt experiment of de toekomst?
}

\author{
W. Sorgdrager
}

\section{Samenvatting}

Sedert 1999 mogen de instellingen voor hoger onderwijs, in plaats van via het centrale systeem van loting, tot een maximum van $50 \%$ zelf studenten decentraal toelaten, op basis van criteria die door de instellingen zelf worden opgesteld. De bedoeling van de wet is dat de aankomende studenten meer invloed krijgen op hun eigen toelating. Met de nieuwe toelatingsprocedure is nu drie jaar gewerkt, met wisselende waardering. Sedert de inwerkingtreding van de wet hebben zich echter ontwikkelingen voorgedaan waardoor het thema 'selectie' een andere betekenis heeft gekregen. Deze betreffen zowel het voortgezet als het hoger onderwijs. Voorts dwingen maatschappelijke ontwikkelingen waarbij de instellingen meer en meer als concurrenten van elkaar worden beschouwd tot onderscheiding en profilering.

De begeleidingscommissie is van mening dat deze ontwikkelingen wijzen in de richting van meer eigen verantwoordelijkheid van de instellingen, ook voor de toelating van de eigen studenten. Besluiten die te maken hebben met de toelating tot het hoger onderwijs moeten daarom in de brede context van deze ontwikkelingen genomen worden.

\section{Inleiding}

De naam Meike Vernooy is in onderwijsland waarschijnlijk nog wel bekend. De leerlinge die slaagde voor haar eindexamen voortgezet onderwijs met een onwaarschijnlijk hoog cijfergemiddelde. Ze wilde graag geneeskunde studeren, had daar ook al het één en ander voor gedaan, maar werd uitgeloot. Waarschijnlijk was ze niet de enige met zulke hoge cijfers die dat overkwam, maar haar vader was wel degene die de kat de bel aanbond en de publiciteit zocht. In een tijd dat de maatschappelijke acceptatie van het lotingsysteem voor het hoger onderwijs niet meer vanzelfsprekend was. Iemand die sterk gemotiveerd is en bovendien een goed eindexamenresultaat heeft behaald zou toch de studie van zijn keuze moeten kunnen volgen! Het lotingsysteem houdt te weinig rekening met individuele kwaliteiten, zo waren de algemene klachten.
Uiteindelijk leidde de discussie in 1999 tot twee belangrijke veranderingen in de wet: iedereen die een gemiddeld eindexamencijfer haalt van 8 of meer wordt, bij een examen met het juiste vakkenpakket, zonder meer toegelaten tot de studierichting van zijn of haar keuze. En verder mogen de instellingen voor hoger onderwijs, in plaats van via het centrale systeem van loting, voor die studierichtingen waarvoor een numerus fixus is ingesteld tot een maximum van $50 \%$ zelf decentraal studenten toelaten. Van die 50\% moeten wel de 8-plussers die al rechtstreeks worden toegelaten, worden afgetrokken. ${ }^{1}$

\section{Een experiment}

De bedoeling van de wet is dat de aankomende studenten meer invloed krijgen op hun eigen toelating. De instellingen moeten zelf criteria voor toelating opstellen. Deze kunnen van alles bevatten, maar juist niet de eindexamencijfers. 
De wetswijziging is bedoeld als een experiment, dat na drie jaar wordt geëvalueerd. Gedurende die drie jaar kan met de mogelijkheid van decentrale toelating gewerkt worden. Na de evaluatie zal een beslissing genomen worden over de toekomst van de toelating. Dat wil zeggen: een beslissing of de wet blijft zoals hij nu is, met de mogelijkheid van decentrale toelating, of een wijziging. In de memorie van toelichting bij het wetsontwerp wordt aangegeven dat voor de toekomst nog niets vastligt. Het kan zijn dat men weer teruggaat naar het oude lotingsysteem maar het andere uiterste, de volledige vrijheid van de instellingen is ook mogelijk.

Niet iedereen was even enthousiast over deze experimenteermogelijkheid. Binnen het onderwijs is nog steeds een grote groep voorstander van het lotingsysteem. Om verschillende redenen. Principieel, omdat iedereen een gelijke kans moet hebben, principieel omdat eindexamencijfers niets zeggen over de capaciteiten van een aankomende student, praktisch omdat het wel gemakkelijk is als vanuit een centraal punt de toelating wordt geregeld. En ongetwijfeld zijn er nog wel meer redenen.

De medische faculteiten, die in feite de aanleiding waren voor dit experiment, zaten er niet echt op te wachten, hoewel men onderkende dat er onder de uitgelotenen zeker goede medische studenten en toekomstige artsen zouden zitten. Het studierendement in de geneeskundefaculteiten is voor Nederlandse begrippen ongekend hoog: het ligt op ruim $80 \%$. Voor de vergelijking: er zijn faculteiten waar net de 50\% wordt gehaald. Toch sprak men af aan het experiment mee te doen, maar dit in elk geval voorlopig te beperken tot $10 \%$ van het aantal beschikbare plaatsen.
Enkele andere opleidingen stonden er positiever tegenover en bestemden ook een ruimer percentage voor de decentrale toelating. Bij het wetenschappelijk onderwijs waren dit bijvoorbeeld tandheelkunde en diergeneeskunde. In het Hoger Beroeps Onderwijs (HBO), waar veel meer ervaring was met decentrale toelating (en in dit verband was de benaming 'selectie' ook niet taboe) was men juist in de afgelopen jaren meer overgegaan naar de centrale loting. Toch was er een aantal instellingen dat belangstelling had voor de nieuwe toelatingsmogelijkheden, zoals de opleiding journalistiek en opleidingen in de sfeer van toerisme.

In de politiek was men uiteraard zeer benieuwd naar het verloop van het experiment. Hoewel er steeds met nadruk wordt gesproken over 'decentrale toelating' en de term 'selectie' zoveel mogelijk wordt gemeden, betekent dit experiment toch een doorbreking van het taboe dat in vele kringen op 'selectie' rust. Bij decentrale toelating moet immers geselecteerd worden.

Ten behoeve van het experiment werd een begeleidingscommissie ingesteld, ${ }^{2}$ waarin vertegenwoordigd zijn: het Wetenschappelijk Onderwijs (WO), HBO, Voortgezet Onderwijs (VO), studenten en een vertegenwoordiger van één van de betrokken beroepsgroepen, in dit geval geneeskunde. Plus een onafhankelijke voorzitter in de persoon van ondergetekende. Waar heeft dit in de praktijk toe geleid?

\section{Criteria}

In de eerste plaats moesten de instellingen criteria opstellen voor de toelating. Dat bleek niet mee te vallen. Om twee redenen niet. Als cijfers en specifieke cognitieve vaardigheden niet de bedoeling zijn, wat dan wel? Verder was het de vraag hoe het systeem hanteerbaar blijft als er voor weinig plaatsen veel gegadigden zijn. 
Het eerste jaar waarin decentrale toelating mogelijk was, was het studiejaar 2000-2001. Maar aangezien het vrij kort dag was na de inwerkingtreding van de wet, maakten uiteindelijk maar enkele opleidingen van deze mogelijkheid gebruik: 8 HBO- en 3 universitaire opleidingen, waaronder twee geneeskunde opleidingen, te weten Utrecht en Leiden. De problemen lagen in het formuleren van de criteria, waarvoor men toch meer tijd nodig had. Het volgende studiejaar waren er dan ook meer deelnemende instellingen.

De begeleidingscommissie heeft de gehanteerde criteria kritisch bekeken. Het doel van de wet was immers dat de aankomende student meer kans kreeg 'het lot in eigen hand te nemen'. Motivatie en specifiek talent waren voor de decentrale toelating doorslaggevende eigenschappen. $\mathrm{Er}$ zijn ook subsidies verstrekt voor de ontwikkeling van criteria en handreikingen gegeven, via bijvoorbeeld ervaringen met selectie in het buitenland.

Maar naast de inhoudelijke kant was er een praktisch probleem: de opvang van de grote aantallen aankomende studenten die bij deze procedure betrokken zijn. Om werkelijk op individueel niveau te kunnen selecteren moet een eerste schifting worden gemaakt. De instellingen hebben in deze fase behoefte aan vaste objectieve criteria, zodat de groep gegadigden wat kleiner van omvang wordt. De neiging bestaat dus om het te zoeken in specifieke vakken in het vakkenpakket, een achtste vak, een al afgeronde andere opleiding, een buitenlandse vooropleiding, et cetera. In de volgende fasen wordt het interessanter en persoonlijker: gevraagd worden bijvoorbeeld het schrijven van een sollicitatiebrief, een essay, een bepaalde opdracht, colleges volgen, een sollicitatiegesprek. De opleidingen journalistiek testen op taalvaardigheid, tandheelkunde onderzoekt specifieke mo- torische vaardigheden, toerisme kijkt naar buitenlandse en andere ervaring.

\section{Ervaringen}

In dit artikel zal niet specifiek worden ingegaan op alle ervaringen die zijn opgedaan. Een uitvoerig overzicht daarvan is te vinden in de jaarlijkse rapportages van de Begeleidingscommissie en in het eindrapport. Naar de mening van de commissie is een aantal ontwikkelingen die sinds de wetswijziging hebben plaatsgevonden van minstens zo groot belang voor de toekomst van de toelating van studenten tot het hoger onderwijs. Hier wordt volstaan met een aantal hoofdlijnen.

Er zijn in het hoger onderwijs ongeveer 60 opleidingen die gebruik zouden kunnen maken van de mogelijkheid van decentrale toelating: ruim 40 in het $\mathrm{HBO}$ en 20 in het WO. In 2000 hebben 12 opleidingen dat ook daadwerkelijk gedaan, in 2001 waren dat er 13 en in 2002 waren het er 21. Het aantal HBO-opleidingen is minder geworden, in het WO is de belangstelling juist toegenomen.

Er zijn twee hoofdredenen waardoor opleidingen afzien van decentrale toelating: het is niet meer nodig, omdat alle aangemelde studenten geplaatst kunnen worden, en het is erg ingewikkeld. Het is moeilijk om goede criteria te ontwikkelen, de procedures kosten erg veel tijd en de logistiek in de samenhang met de Informatie Beheer Groep (IBG) is nogal gecompliceerd. ${ }^{3}$

De tijdsinvestering is bijvoorbeeld voor de universiteit van Leiden de reden om in 2003 niet meer decentraal toe te laten, ondanks de positieve ervaringen van degenen die vanuit de universiteit aan het proces hebben deelgenomen. Leiden bood de kandidaten die na de eerste selectieronde overbleven gedurende een bepaalde periode de mogelijkheid speciale colleges en werkgroepen te volgen. Met alle deelne- 
mers werd individueel uitvoerig gesproken. Het was erg veel werk voor slechts een kleine groep studenten. Nu alle capaciteit moet worden ingezet voor de uitbreiding van het aantal plaatsen voor geneeskunde kan de faculteit zich in feite deze investering niet meer permitteren.

Anderzijds zijn er juist weer instellingen die overwegen voor het volgend jaar de decentrale toelating in te voeren. Het gaat daarbij vooral om opleidingen in de economische en bedrijfskundige sfeer.

Medio februari is het eindrapport van de Begeleidingscommissie verschenen. ${ }^{4}$ Er zijn enquêtes gehouden onder deelnemers over onder andere de waardering van de nieuwe wettelijke mogelijkheden en de procedure zelf. Schooldecanen en studenten die met meer dan een 8 hun eindexamen haalden, staan het meest positief tegenover de $8+$ regeling. Bijna alle anderen hebben de meeste waardering voor de decentrale toelating. De gewogen loting scoort het laagst. De waardering onder de schooldecanen voor de nieuwe toelatingsmogelijkheid is lager dan bij de andere ondervraagden. Dat heeft onder andere te maken met het feit dat iedere instelling verschillende criteria hanteert. De informatie is onvoldoende, men is het overzicht kwijt. Of het ook een inhoudelijk oordeel is, is helaas niet bekend. 5

Van de criteria die men het meest relevant acht voor de toelating scoren de motivatie om de opleiding te volgen en om het beroep uit te oefenen het hoogst. Daarna volgen een relevante vooropleiding, sociale en communicatieve vaardigheden. Nauwelijks van belang zijn geslacht, levensbeschouwing en etniciteit. De hoogte van het eindexamencijfer scoort gemiddeld.

De algemene conclusie is dat er bij de geënquêteerden wel draagvlak is voor decentrale toelating. De Begeleidingscom- missie is echter ook van oordeel dat het experiment zo kleinschalig was, dat het trekken van algemene conclusies niet goed mogelijk is.

Vermeldenswaard is wel dat waar de wet uitgaat van het belang van de student (lot in eigen hand), de instellingen de mogelijkheden voor decentrale toelating voornamelijk benaderden vanuit het belang van de instelling, bijvoorbeeld door ernaar te streven 'de beste' studenten binnen te halen of om het rendement in de opleiding te verhogen.

\section{Ontwikkelingen}

Van groot belang voor de toekomst zijn de sinds 1999 veranderde omstandigheden in zowel het hoger als het voortgezet onderwijs. Het gaat om ontwikkelingen die zich vrijwel autonoom voordoen, zonder dat een principiële discussie is gevoerd over de gevolgen ervan. Nooit is duidelijk geworden of het gewilde gevolgen zijn. Maar hoe dan ook, ze zullen in elk geval van invloed zijn op het onderwijs en daarmee op het denken over toelating en selectie. ${ }^{6}$

Lange tijd is 'selecteren' min of meer taboe geweest. Een gevolg van het gelijkheidsdenken dat het onderwijs lange tijd heeft beheerst en op veel plaatsen nog beheerst. Het is natuurlijk waar dat de hoogste cijfers geen garantie op succes bieden en het omgekeerde is ook waar: heel wat scholieren en studenten die qua cijfers niet zo hoog scoren blijken in hun vak uitstekend te zijn. Maar het is toch wel zo dat in het algemeen studenten die een 8 gemiddeld voor hun eindexamen haalden het beter doen dan degenen die net met een 6 slaagden. Daarbij moet wel vermeld worden dat het ontbreken van selectie ook niet direct motiverend werkt om een beter resultaat te halen dan strikt nodig is. Dat is jammer, want daarmee gaat uiteindelijk potentie verloren. 
Toch ziet men steeds meer, bijna sluipenderwijs, dat selecteren 'mag'. Soms openlijk, een enkele keer zelfs op cijfers. De $8+$ is immers geaccepteerd. Maar men geeft de voorkeur aan andere criteria, mede omdat een eindexamencijfer op de ene school iets anders voorstelt dan op de andere.

Bij de decentrale toelating wordt door alle instellingen die aan deze procedure meedoen op de één of andere manier gekeken hoe de student zijn speciale motivatie tot uitdrukking heeft gebracht.

Kort na de start van het experiment met decentrale toelating zijn in het voortgezet onderwijs de vakkenpakketten vervangen door profielen en zijn er meer vrije keuzemogelijkheden gekomen. Voor het hoger onderwijs is dat een probleem bij het bepalen van criteria voor toelating: moeten de criteria zodanig zijn opgezet dat alle scholen in gelijke mate leerlingen hieraan kunnen laten voldoen? In beginsel natuurlijk wel, maar in de praktijk is dat nauwelijks haalbaar. Leerlingen worden beperkt door wat de school kan aanbieden. De mankracht en middelen laten in het algemeen de theoretisch aanwezige mogelijkheden niet toe.

Scholen gaan bij de invulling van hun programma's bovendien steeds vaker uit van een eigen strategische visie op eigen plaats en functioneren. Deze visie is afhankelijk van de context van de school. Die eigen visie kan bijvoorbeeld het streven naar een topschool inhouden, maar ook een keuze voor het wegwerken van achterstanden. Dat kan gevolgen hebben voor het eindresultaat. Daarbij komt dat het belang van het centraal schriftelijk eindexamen vergeleken met vroeger in omvang is afgenomen. Destijds werd in zeven vakken centraal schriftelijk geëxamineerd, dus een bijna volledige centrale schriftelijke toetsing, met één eindniveau.
$\mathrm{Nu}$ zijn het weliswaar ook zeven vakken, maar er zijn in totaal geen zeven, maar veertien vakken. Zo kan er dus een verschil in kennis en vaardigheden bij de aankomende studenten ontstaan. Een discussie over de gewenste uniformiteit van het eindniveau is tot dusverre nauwelijks gevoerd. Althans niet in de politiek. In de praktijk kan verwacht worden dat het hoger onderwijs, geconfronteerd met die verschillen in eindniveau, zich gaat afvragen of nog genoegen genomen kan worden met het centraal schriftelijk eindexamen of dat er nog nadere specifieke eisen gesteld moeten worden. De druk op selectie aan de poort zal hierdoor waarschijnlijk toenemen en bovendien zou het wel eens relevant kunnen worden op welke school iemand zijn einddiploma heeft gehaald.

Tegelijkertijd vindt bij opleidingen in het hoger onderwijs langzamerhand meer profilering plaats en het liefst zoekt men daar de studenten bij die in dat profiel passen. In het medisch wetenschappelijk onderwijs staat men, zo is de Commissie gebleken, huiverig ten opzichte van profilering, maar opleidingen in de sfeer van bedrijfswetenschappen en business-administration en veel HBO-instellingen streven er juist wel naar.

Universiteiten en hogescholen worden geprikkeld om met elkaar te concurreren; de instellingen zullen uiteindelijk ook gaan concurreren om de beste studenten. Tenslotte levert dat ook het meeste geld op. Universiteiten kunnen bepaalde verbanden aangaan met scholen in de regio, of met scholen van een gelijke gezindheid. Zou het zo zijn dat aankomende studenten van die scholen meer kans hebben bij de universiteit dan anderen?

Hoe zal het gevoel voor de eigen verantwoordelijkheid bij de instroom zich bij de universiteiten en hogescholen ontwikkelen als de financiën steeds meer afhanke- 
lijk worden gesteld van de studieresultaten? Zouden universiteiten een numerus fixus instellen om alleen die studenten toe te hoeven laten waarvan men een goed studieresultaat en dus het meeste financiële rendement verwacht? Of moet er helemaal geen numerus fixus nodig zijn om decentraal te mogen selecteren? Waar worden die studenten opgevangen die wel aan de kwalificaties voldoen, maar niet aan de extra kwalificaties die sommige opleidingen stellen?

Dit zijn vragen en discussies die gaan over selecteren bij de poort. Een gevoelig punt, maar wel duidelijk. Als daar wordt geselecteerd, gebeurt het openlijk, met algemeen bekende criteria. We weten natuurlijk dat in de loop van de opleiding voortdurend wordt geselecteerd. En hoe open en toetsbaar zijn die criteria?

Er wordt geselecteerd na het basisonderwijs en na de brugklas. In het voortgezet onderwijs zal bij de profielkeuze misschien niet zozeer geselecteerd, maar toch wel gestuurd worden. In het hoger onderwijs vindt selectie plaats bij bijvoorbeeld de toekenning van beurzen, een student-assistentschap, een mooie stageplaats. Hoe gaat men om met talentvolle studenten en wie bepaalt wat een talentvolle student is?

Ook binnen de bachelor-masterstructuur zal selectie plaatsvinden. Volgens de politiek mag de universiteit zelf bij aansluitende opleidingen geen nadere criteria stellen voor toelating tot de eigen masterstudie. Maar wie zijn masters bij een andere universiteit wil doen, of voor een niet aansluitende masters opteert, zal daarvoor wel geselecteerd mogen worden. Welke criteria zijn toelaatbaar en wie bepaalt dat?

Kortom, het niet aangaan van de discussie over selectie is niet veel anders dan de kop in het zand steken. En dan later wakker worden en verbaasd constateren dat de wereld ongemerkt is veranderd. Er wordt steeds meer aan de instellingen zelf overgelaten, zoals vroeger de private instellingen zelf konden bepalen wie ze toelieten en op welke gronden. Het wordt tijd om de vraag te stellen waar en tot hoe ver de verantwoordelijkheid van de overheid in dit verband strekt. In hoeverre kunnen de rechten die verbonden zijn aan het einddiploma van het voortgezet onderwijs ook werkelijk tot gelding worden gebracht nu het erop lijkt dat de verschillen tussen de diploma's groter worden?

Toen de Begeleidingscommissie werd ingesteld ging het slechts over selectie bij decentrale toelating. $\mathrm{Nu}$ is het landschap zo veranderd dat die vraagstelling waarschijnlijk in die context niet meer de belangrijkste is. Maar er zijn zeer principiële vragen bijgekomen waarover dringend discussie moet plaatsvinden.

\section{Literatuur}

1. Wet van 3 april 1999, tot wijziging van de Wet op het hoger onderwijs en wetenschappelijk onderzoek, houdende aanpassingen in het systeem van selectie voor opleidingen waarvoor een toelatingsbeperking is vastgesteld. Staatsblad 1999 (nr. 170).

2. Regeling Minister OC\&W, nr. WO/BS/99/8866.

3. Begeleidingscommissie Decentrale Toelating. Rapportages voor het studiejaar 2000/2001 en 2001/2002

4. Begeleidingscommissie Decentrale Toelating. De juiste student op de juiste plaats. Februari 2003: www.minocw.nl/onderwijs/hogeronderwijs.

5. Begeleidingscommissie Decentrale Toelating. Lot in eigen hand. Evaluatie-onderzoek door het IOWO. Februari 2003: www.minocw.nl/onderwijs/hogeronderwijs.

6. Begeleidingscommissie Decentrale Toelating. Decentrale toelating in een veranderende context. Analysedocument behorende bij de tussenrapportage decentrale toelating 2001-2002.

De auteur:

Mw. mr. W. Sorgdrager is voorzitter van de Raad voor Cultuur.

Correspondentieadres:

Raad voor Cultuur, R.J. Schimmelpennincklaan 3, Postbus 61243, 2506 AE Den Haag, tel: 070-3106686, fax: 070-3614727,cultuur@cultuur.nl. 


\section{Summary}

In The Netherlands, admission to university is, for a number of studies, regulated through a national balloting system. Since 1999 institutions for higher education are allowed to admit a maximum of 50\% of their students on the basis of criteria formulated by the institutions themselves. This new admission (selection) procedure has been used for three years now with varying appraisal. Since the new law took effect, however, certain developments in the fields of both secondary school and higher education altered the meaning of the word 'selection'. In addition, social developments that force institutions to more and more compete with one another, urge to differentiate between and profile students. The steering committee feels that these developments point towards more responsibility of the institutions themselves, the admission of their own students included. Decisions concerning the admission to higher education must therefore be taken in the broader context of these developments. 